\title{
Employees' pro-environmental
}

behaviours (PEBs) at international hotel

chains (IHCs) in China: The mediating

role of environmental concerns (ECs)

\section{Zhang, Jinhua}

http://hdl.handle.net/10026.1/13744

10.1016/j.jhtm.2019.03.007

Journal of Hospitality and Tourism Management

Elsevier

All content in PEARL is protected by copyright law. Author manuscripts are made available in accordance with publisher policies. Please cite only the published version using the details provided on the item record or document. In the absence of an open licence (e.g. Creative Commons), permissions for further reuse of content should be sought from the publisher or author. 


\section{Employees' pro-environmental behaviours (PEBs) at international hotel chains (IHCs) in China: The mediating role of environmental concerns (ECs)}

\section{Author Details:}

1. Mr. Jinhua Zhang* University of Plymouth, UK (Corresponding author*) Plymouth Business School, University of Plymouth, Plymouth, PL4 8AA Email: jinhua.zhang@plymouth.ac.uk

2. Dr. Rong Huang University of Plymouth, UK

Plymouth Business School, University of Plymouth, Plymouth, PL4 8AA Email: rong.huang@plymouth.ac.uk

\section{Author Bio}

Mr. Jinghua Zhang is doing his doctoral study at University of Plymouth (UK). He obtained his Master of Human Resource Management from University of Leeds (UK). His research interests include hotel staff motivation, job performance and satisfaction, and tourism in China.

Dr. Rong Huang is an Associate Professor from University of Plymouth (UK). Her research interests focus on aspects of the tourism phenomenon and published articles in relation to international student travel, employability, food tourism and intermediation. 


\begin{abstract}
To understand how to enhance employees' PEBs of IHCs in China, the study investigated interactions of employees' autonomous motivation (AM), controlled motivation (CM), ECs and PEBs. A quantitative approach was employed to test the hypotheses of the study. In total, 181 valid responses from IHCs in Chongqing (one of four municipalities) were collected with an online questionnaire method. Data analysis by SPSS Statistics 24 and SmartPLS 3.2.7, the study verified that AM, CM and ECs were directly and positively related to employees' PEBs. Besides, the study found that ECs were as a mediator of relationship between AM and employees' PEBs. The results presented principally practical suggestions: IHCs need to combine employees' AM with CM for PEBs improvement, and employees' environmental attitudes (e.g. ECs) should also be a focus rather than merely concentrating on how employees perform their PEBs through motivation.
\end{abstract}

Key words: Pro-environmental behaviours, International hotel chains, Employee motivation

\title{
1. Introduction
}

Along with climate change becoming a serious global issue, the hotel industry has been aware of which it is necessary to employ green initiatives to face this issue (Chou, 2014; Rahman et al., 2012). To successfully implement hotels' green initiatives, the extent to which employees willingly and actively perform pro-environmental behaviours is critical (Daily et al., 2009). IHCs have dominated the global hotel market (Al-Sabi, 2017), so their employees' PEBs are important as a positive environmental example for the hotel industry.

Employee motivation is a primary element that is related to behaviours and attitudes in the research (Arnold et al., 2016). Kim et al. (2016) pointed out that the majority of previous studies have demonstrated impacts of employee motivation on job performance and satisfaction, but little research addressed the relationship between employee motivation and PEBs. Selfdetermination theory highlights the differences between autonomy and control and the critical role of autonomy during the motivation process (Gagné \& Deci, 2005). This theory has been successfully employed to understand employee motivation in the workplace (Gagné et al., 2015; Gatling et al., 2016; Welters et al., 2014), and it is also linked with PEBs in the research (Darner, 2009). Kim et al. (2016) indicated that as employees are self-determined, they are able to persist in their PEBs. Therefore, it is worthwhile to employ self-determination theory as a framework to explore influences of employee motivation on PEBs in the hotel industry.

China showed the rapid growth of economy and the hotel industry in the last 30 years, and IHCs' properties have distributed nationwide (Law et al., 2014; Zhang et al., 2012). However, in the current research of the hotel industry in China, employees' PEBs have received little attention from researchers (Daily et al., 2009; Graves et al., 2013; Kim et al., 2016). The previous studies by Kim et al. (2016) and Lee et al. (2014) demonstrated that environmental concerns were directly related to PEBs, but there is rare research about the interaction of employee motivation and ECs in facilitating PEBs at IHCs in China. Furthermore, China has become a main contributor to air pollution (e.g. $\mathrm{CO}_{2}$ emissions and atmospheric sulphur oxides and chlorofluorocarbons) all over the world (Fang et al., 2016), and Chen et al. (2011) argued that there is lack of pro-environmental behaviours and attitudes in China, because people seem to think protecting environment is the government's responsibility. Thus, it is required to focus on research regarding PEBs improvement in China, and call for the focus shift of IHCs from expansion to environmental investments. 
Against this background, the study aims to investigate and assess the roles of employee motivation and ECs in enhancing PEBs at IHCs in China. To meet the aim, the structure of this study consists of five sections. Section one presents rationale for this research. Section two proposes the theoretical model and seven hypotheses, based on a critical review of literature about the research of international hotels in China, PEBs, self-determination theory, AM, CM and ECs. Section three explains the details of data collection and analysis. Section four presents the study's findings to demonstrate whether the hypotheses are supported. Section five discusses key findings in relation to previous literature. Section six concludes the key findings and highlights the importance of the research related to practical and theoretical implications.

\section{Literature review}

\subsection{The research of international hotels in China}

The rapid development of IHCs in China led to researchers' extensive attention to the Chinese hotel research. Tsang \& Hsu (2011) showed a deep increase of published articles related to hotel research in leading English language academic journals. In their research, it is indicated that consumer behaviour and hotel development are two main research themes, due to the increase of international commerce and international hotels' investment in China. Law et al. (2014) adopted a systematic approach to review articles regarding hotel sectors in China and they found that 72 of 93 articles included into SSCI-listed journals were published after 2009, and human resource management and strategic management were frequently researched topic for international hotel academics. Comparing between Chinese-language and English-language academic articles in leading journals of tourism and hospitality, Tsang et al. (2015) demonstrated that service quality obtained more concentration from Chinese than international researchers, since IHCs expanded in China that increased the competition within the hotel industry. Although the research of Law et al. (2014), Tsang et al. (2015) and Tsang \& Hsu (2011) presented the increasing attention was received regarding the research of international hotels in China, pro-environmental issues were not identified as a main research theme. It is required to concentrate on the research of pro-environmental issues so that PEBs can attract more attention and improve employees' PEBs in practice.

Furthermore, research regions in China were uneven. Law et al. (2014) indicated that most of studies collected data from eastern and southern cities (e.g. Beijing, Shanghai and Guangzhou) in which the properties of IHCs were mainly distributed, but few conducted research in central and western cities. Along with the growth of IHC in the Chinese central and western regions, researchers gradually transferred their attention to these regions for comprehensively understanding the development of IHCs in China (Zhang et al., 2012). Thus, this study was an attempt to extend research scope in the central and western regions in China.

\subsection{Pro-environmental behaviours}

Graves et al. (2013, p. 81) conceptualised employees' PEBs as “a broad set of environmentally responsible activities such as learning more about the environment, developing and applying ideas for reducing the company's environmental impact, developing green processes and products, recycling and reusing, and questioning practices that hurt the environment". Kim et al. (2016) argued that enhancing employees' PEBs promotes corporate social responsibility in terms of natural resources preservation and environmental degradation's alleviation. Furthermore, employees' PEBs play a critical role in environmental management systems 
implementation. Only employing environmental management systems is inadequate for each organisation to develop greening, because successful environmental programs normally rely on whether employees' behaviours are consistent with these programs (Robertson \& Barling, 2013).

However, employees' PEBs improvement still faces some challenges. PEBs are normally as an extra-role behaviour that is not a compulsory requirement for employees' jobs and does not result in many rewards (Chou, 2014). It may restrict employees' positivity for proenvironmental activities. Additionally, a behaviour is controlled by past habit and performance, so employees without strong pro-environmental awareness in the past are faced with a challenge to develop their PEBs in the workplace (Chan et al., 2014). In China, on the one hand, education development between urban and rural areas is still imbalanced and the economic development is the focus nationwide; on the other hand, people tend to depend on the government for environmental protection (Chen et al., 2011). Therefore, there is lack of proenvironmental awareness and PEBs.

As indicated previously, pro-environmental issues were not a prevalent research theme in the hotel industry (Law et al., 2014; Tsang et al., 2015; Tsang \& Hsu, 2011). However, increasing researchers pay attention to this theme in the recent years (Kim et al., 2018). Kim et al. (2018) made a systematic review to indicate that there were only three articles about proenvironmental issues published in the leading journals of tourism and hospitality between 1987 and 2011, but increased to seven between 2012 and 2016. To extend the research related to pro-environmental issues, the study was a desirable attempt through investigating employees' PEBs.

\subsection{Self-determination theory and hypotheses development}

\subsubsection{Self-determination theory}

Self-determination theory, which explains the crucial role of autonomy, has been successfully used for employees' PEBs in the workplace by understanding employee motivation (Darner, 2009; Graves et al., 2013; Kim et al., 2016). Intrinsic and extrinsic motivation are two types of employee motivation at work (Ryan \& Deci, 2000). Intrinsic motivation depends on the work itself, which is consistent with personal inherent satisfaction (Deci \& Ryan, 2000). However, self-determination theory indicates that intrinsic motivation is a type of AM which highlights that employees work on an activity that fits with their value and goals (Gagné \& Deci, 2005; Welters et al., 2014).

In contrast to intrinsic motivation, employees are extrinsically motivated, as they do an activity for instrumental value (Gagné et al., 2015). Self-determination theory argues that extrinsic motivation has changes due to the differences of autonomy's degree (Ryan \& Deci, 2000). For example, an employee completed a task to avoid criticism by the line manager; another employee did it, because he/she thought it was useful for the career goal. For two employees, motivation is extrinsic, but the degree of autonomy is different. The autonomy for the second employee is stronger. According to Arnold et al. (2016), self-determination theory divides extrinsic motivation into four types: external regulation (rewards or penalties), introjected regulation (self-esteem), identified regulation (personal importance), and integrated regulation (expression of self). 
Among four types of extrinsic motivation, the autonomous degree of identified regulation and integrated regulation is strong, so some researchers (e.g. Gagné et al., 2015; Ryan \& Deci, 2000; Welters et al., 2014) indicated that identified regulation, integrated regulation, and intrinsic motivation are classified as autonomous motivation. In contrast, external regulation and introjected regulation are included into $\mathrm{CM}$ which highlights that employees work on an activity as they believe they need to do it (Gagné et al., 2015; Graves et al., 2013).

\subsubsection{Autonomous and controlled motivation}

Generally, AM results in better performance in the workplace than CM, because the nature of AM which is self-expression or self-consistent contributes to performance (Gagné \& Deci, 2005). In contrast, feeling required to do an activity which is the trait of CM may prevent employees from desirable performance (Gagné \& Deci, 2005). The previous studies by Graves et al., 2013 and Kim et al., 2016 demonstrated that AM was positively impacted on employees' PEBs. Employees can strive to do an environmental activity better, if the activity fits with their value and goals (Kim et al., 2016). Additionally, PEBs include some complicated and challenging tasks, such as devising green products and bringing in new environmental management systems, so it is crucial to keep employees autonomously motivated and internalise their environmental behaviours (Graves et al., 2013). Thus, the study proposes that:

\section{H1. Employees' AM is positively related to PEBs.}

Although self-determination theory indicates that CM may prevent from good performance (Gagné \& Deci, 2005), some researchers (e.g. Graves et al., 2013; Kim et al., 2016; Welters et al., 2014) argued the importance of CM for employee performance. External regulation is a type of CM, and rewards are as the principal form of external regulation (Ryan \& Deci, 2000). Expectancy theory shows that employees perform a specific behaviour, when they expect that this behaviour will result in desirable rewards (Chiang et al., 2008). The hotel industry is characterised as low pay that negatively influences employees' job attitude and behaviour (Chiang \& Jang, 2008), so rewarding employees may be a viable way to enhance PEBs. In the empirical research of the hotel industry, Graves et al. (2013) and Kim et al. (2016) demonstrated that external motivation (external regulation) is positively related to PEBs. Their research verified the relationship between external regulation and PEBs, but introjected regulation which is the other type of $\mathrm{CM}$ is not included in their research. "Introjected regulation refers to the regulation of behaviour out of internally pressuring forces, such as egoinvolvement, shame, and guilt" (Gagné et al., 2015, p. 179). Introjected regulation is also noteworthy to motivate employees to perform PEBs. For example, if an employee's colleagues and family members perform PEBs, he/she may feel guilty or lose self-esteem without PEBs. Furthermore, employees' PEBs are normally as an extra-role behaviour, which lead to few rewards or punishments (Chou, 2014). In this way, external regulation may not be dependable as a single variable to predict employees' PEBs. Instead, combining external regulation with introjected regulation can be a more reliable predictor of employees' PEBs. Thus, the study proposes that:

H2. Employees' CM is positively related to PEBs.

\subsubsection{Environmental concerns}

ECs refer to "the affect (i.e., worry) associated with beliefs about environmental problems" (Schultz et al., 2004, p. 31). For example, a government's invalid controls over air 
contamination may result in a person's worry about environment (Chan et al., 2014). The term 'environmental concern' can also be interchanged with environmental attitude (Luo \& Deng, 2008). Because employees' motivation impacts on attitudes (Ambrose \& Kulik 1999; Arnold et al., 2016), ECs may be promoted by effective motivation measures. Self-determination theory indicates that internalising value and regulation produces the positive attitude (Gagné \& Deci, 2005). Thus, this study proposes that:

H3. Employees' AM is positively related to environmental concerns.

Clark et al. (2003) demonstrated that external factors resulted in positive environmental attitude. Furthermore, the theoretical model proposed by Kim et al. (2016) presents that external regulation had a positive impact on ECs. According to (Gagné \& Deci, 2005), external regulation is included into controlled motivation, and internalising external demand produced a positive attitude. Based on their research, this study proposes that:

H4. Employees' CM is positively related to environmental concerns.

According to theory of planned behaviour, behaviours are more favourable predicted by intentions which are decided by attitudes (Ajzen and Madden, 1986). Specifically, Chan et al. (2014) and Lee et al. (2014) demonstrated that ECs were positively related to employees' PEBs in the hotel industry. To verify that more green practices are adopted by employees who have significant concerns about environmental protection at IHCs in the Chinese context, this study proposes that:

H5. ECs are positively related to PEBs.

Previous studies (Chan et al., 2014; Chen et al., 2011; Clark et al., 2003; Kim et al., 2016) indicated that ECs or environmental attitudes had a direct relationship with employee motivation, PEBs or both. To extend the understanding of how and why employee motivation impacts on PEBs, it is worthwhile to consider ECs as a mediator. Thus, this study proposes that:

H6. ECs mediate the relationship between AM and PEBs

H7. ECs mediate the relationship between CM and PEBs

To summarise, the study reviewed literature about AM, CM, ECs and employees' PEBs to develop seven hypotheses for the investigation of employees' PEBs improvement. The theoretical model is presented as figure 1.

Fig. 1. The theoretical model

\section{Methodology}

\subsection{Questionnaire design and measurement of construct}

The study adopted a quantitative approach to test the hypotheses. The original version of the questionnaire was in English, and then converted into Chinese by back translation method, which guaranteed the consistency (Brislin, 1976). The demographic profiles of respondents consisted of four variables (presented on Table 1). Apart from respondents' profiles, the 
questionnaire had four sections, which were AM, CM, ECs and employees' PEBs, respectively. Each section was measured by multiple items, and all items in each section were rated by respondents with 7-point Likert scale (1 means 'strongly disagree/no awareness/the least consistent' and 7 means 'strongly agree/fully aware/the most consistent').

Referring to Gagné et al. (2015), Graves et al. (2013) and Kim et al. (2016), employee motivation was measured from two sections: AM and CM, and each section has five items (presented on Table 3). Six items were adopted from Chan et al. (2014) and Kim et al. (2016) to measure ECs. For the section of employees' PEBs, nine items were employed from Graves et al. (2013) and Kim et al. (2016). Items of ECs, and employees' PEBs were shown on Table 2 .

To confirm the validity of the questionnaire design, the initial questionnaire was reviewed by both Chinese and English academic experts for comments and refinements. Hung \& Law (2011) indicated that low cost and fast response are top two advantages of an online questionnaire method. Therefore, an online questionnaire link was made and then sent to some employees working at IHCs in China for pilot testing. Fink (2012) indicated that the number for a pilot testing was 10 at minimum. The study collected 15 responses in March 2017, and the comments were given to the researcher. The main amendment was the question of employee classification converted from required to optional, because some of respondents thought it might violate the privacy. After changes were made through pilot testing, the questionnaire was finalised.

\subsection{Data collection}

An online questionnaire was employed to collect data during April and May 2017. Respondents were employees working in IHCs in Chongqing of China. Chongqing, the Chinese municipality as well as the centre city of China Western Development, showed rapid economic development in recent years (Chongqing Municipal People's Government, 2017). For example, the GDP growth rate in 2015 and 2016 ranked first in China (China, 2017). Moreover, number of 5- and 4-star hotels had a rise from 31 in 2005 to 82 in 2015, which increased 62.2 percent in ten years (Chongqing Municipal People's Government, 2017). Due to rare research of tourism and hospitality in the Chinese western region, results of this survey can fill this gap. The questionnaire link was initially distributed to employees who worked in IHCs in Chongqing by respondents who completed the pilot testing. In short, snowball sampling that the researcher needed to ask cases for more cases was employed in this study (Saunders et al., 2016). A total of 206 questionnaires were collected of which 181 questionnaires were usable. Hair et al. (2011, p. 144), Kock \& Hadaya (2018, p. 232) and Peng \& Lai (2012, p. 469) indicated that "PLSSEM minimum sample size should be equal to the larger of the following: (1) ten times the largest number of formative indicators used to measure one construct". Each formative construct had five indicators (presented on Table 3), so sample size of the study met the requirement of minimum sample size.

\subsection{Data analysis}

The first step of data analysis was to employ SPSS Statistics 24 to screen data for quality guarantee and to present the results of respondents' profile. Second, software Smart PLS 3.2.7 was applied to assess measurement and structural models. The principal reason why PLS-SEM was an appropriate approach for the study was that the measurement model in PLS-SEM is made up by reflective and formative constructs (Hair et al., 2017). According to Arnold et al. (2016), AM and CM are driven by some elements (e.g. rewards, goal, or interest) rather than 
these elements reflected by motivation, so it is more favourable to consider AM and CM as formative constructs. ECs and employees' PEBs were appropriate to be seen as reflective constructs, because removing an item of a construct did not change the essence of this construct (Hair et al., 2017). The final step was to analyse mediating role of ECs.

\section{Results}

\subsection{Profile of the respondents}

Respondents' profile was presented in Table 1. There were more females (69.1\%) than males (30.9\%). Most of respondents' education level was below Master's degree. Respondents with Diploma or below represented 39.8\%, and 53.6\% of respondents had a Bachelor degree. More than half of respondents may think enquiring about their position classification violates their privacy, so they did not answer this question. In terms of work experience, the majority of respondents had between 4-10 years (40.9\%), followed by respondents whose work experience was below 3 years (36.5\%). Respondents were from 14 different IHCs, but IHCs from the same group have the identical management system. Therefore, 14 IHCs were included into 9 international hotel groups.

Table 1 Profile of respondents (responses: 181)

Because the study employed snowball sampling, a chain has more properties in Chongqing may provide more responses for the researcher. For example, Hilton in Chongqing currently has four properties (Hilton, 2018), while Banyan Tree has only one (Banyan Tree, 2018). In this way, responses from Hilton took up a high proportion, but Banyan Tree's responses were low. In total, 80 percent of international hotel groups listed by Chongqing Municipal People's Government (2017) were contained.

\subsection{Assessment of reflective and formative measurement models}

Verifying the reflective and formative constructs are required, prior to the assessment of the structural model (Chen \& Huang, 2018). According to Hair et al. (2017), assessing reflective measurement model is based on four steps: internal consistency reliability, indicator reliability, convergent validity and discriminant validity. First, Table 2 indicates that all values of Cronbach's alpha and composite reliability are above 0.80 , which meet the minimal requirement of 0.70 and support internal consistency reliability (Nunnally, 1978). Second, the majority of outer loadings exceed 0.70 which is the minimally required value, and only three are below the 0.70 . However, if deleting outer loadings that are between 0.40 and 0.70 do not increase the values of composite reliability, they can be retained (Hair et al., 2017). After deleting the three loadings, the values of composite reliability are not increased, so the three loadings are retained and indicator reliability is confirmed. Third, average variance extracted (AVE) values are above 0.50 , which is the minimal requirement for convergent validity. Last, for discriminant validity, on the one hand, cross loading of each indicator on the associated construct should be highest; on the other hand, the square root of AVE on the diagonal should have the highest value (Fornell \& Larcker, 1981). The study's results demonstrate that discriminant validity is supported.

Table 2 Assessment of reflective measurement model 
Assessing formative measurement model depends on testing convergent validity, collinearity issues, and the significance and relevance of the formative indicators (Hair et al., 2017). First, redundancy analysis, which requires the path coefficient linking the two constructs to be larger than 0.70, is employed to test convergent validity (Sarstedt et al., 2013). Figure 2 shows that the path coefficients of two formative measurement models are above 0.70 , which confirms the convergent validity. Second, variance inflation factor (VIF) is an indicator of collinearity assessment (Hair et al., 2017). Table 3 shows that all VIF values are below 5, which means that there is no potential collinearity issue. The final step is to test indicators' significance and relevance by Bootstrapping. In Table 3, there are three indicators' outer weights not significant, but their outer loadings are above 0.50 , which indicates that all indicators can be retained. With the verification of the reflective and formative constructs, and the study was able to assess the structural model.

Fig.2. Formative measurement model: Redundancy analysis

Table 3 Assessment of the formative measurement model

\subsection{Assessment of the structural model}

Assessing the structural model is to test hypotheses of the study. The first step of assessment is to test collinearity. Because all VIF values are below the threshold of 5, there is no collinearity issue in the structural model (Chin, 1998). Secondly, to predict the model's accuracy, assessing coefficient of determination $\mathrm{R}^{2}$ is necessary (Hair et al., 2017). The $\mathrm{R}^{2}$ values of PEBs and environmental concerns are 0.531 and 0.335 respectively which represent moderate effects to be explained by their linked exogenous constructs (Hair et al., 2017). Even though $\mathrm{R}^{2}$ values of two endogenous constructs are not deeply strong, they still exceed threshold of 0.10 (Chen \& Huang, 2018). Besides, the $Q^{2}$ values of PEBs and environmental concerns are above the minimal requirement of zero, which indicates that the structural model meets predictive accuracy (Henseler et al., 2009).

Finally, path coefficients and t values are calculated by Bootstrapping to test hypotheses (Chin, 1998). Table 4 presents significance and relevance of the path coefficients. Hypotheses $\mathrm{H} 1-\mathrm{H} 2$ test whether autonomous motivation and controlled motivation would be positively related to PEBs. The results show that autonomous motivation $($ coefficient $=0.329, t$-value $=4.175, p<0.01$ ) and controlled motivation (coefficient $=0.337, t$-value $=4.289, p<0.01$ ) have positive impact on PEBs. Therefore, H1-H2 are supported. Hypotheses H3-H5 assess the relationship between autonomous motivation and environmental concerns, the relationship between controlled motivation and environmental concerns, and the relationship between environmental concerns and PEBs. The results show that autonomous motivation (coefficient $=0.545, t$-value $=6.045$, $p<0.01$ ) is positively related to environmental concerns (coefficient $=0.267, t$-value $=3.548$, $p<0.01)$ which has a positive relationship with PEBs. However, controlled motivation (coefficient $=0.076, t$-value $=1.016, \quad N . S$.) does not have a significant influence on environmental concerns. Thus, $\mathrm{H} 3$ and $\mathrm{H} 5$ are supported, but $\mathrm{H} 4$ is not.

Table 4 Significance and relevance of the path coefficients

\subsection{Mediation analysis}

"A mediator is a variable that accounts for all or part of the relationship between a predictor and an outcome" (Baron \& Kenny, 1986, p. 1176). The significance of direct effect and indirect 
effect decided the mediating role (Hair et al., 2017; Nitzl et al., 2016), and Table 5 illustrated the three mediating effects. The study's results of mediation analysis demonstrated that the relationship between autonomous motivation and PEBs is partially mediated by environmental concerns, but there is no mediator confirmed between controlled motivation and PEBs (presented on Table 6). Thus, H6 was confirmed, but H7 was rejected.

Table 5 Mediating effects

Table 6 Mediation test by Bootstrapping

\section{Discussion}

Due to little research about determinants of employees' PEBs at IHCs in China, this study tested and assessed roles of employee motivation and ECs in facilitating PEBs. The study's results demonstrated that $\mathrm{H} 1$ was supported, and this was consistent with Graves et al. (2013) and Kim et al. (2016). As suggested by self-determination theory, AM leads to desirable performance (Gagné \& Deci, 2005; Welters et al., 2014). The finding reflected the fact that employees internalising their value and regulation about environment increased the extent to which they actively participated the environmental activities and persistently performed PEBs (Kim et al., 2016). H2 was also supported by the research, but the finding indicated that CM was the primary determinant of PEBs, which contradicted the view by Gagné \& Deci (2005) and Gagné et al. (2015) that AM led to more desirable performance than CM. It argued that external factors played an important role in promoting employees' behaviour (Chiang \& Jang, 2008). Moreover, this study extended the work of Grave et al. (2013) and Kim et al. (2016) by assessing the relationship between PEBs and $\mathrm{CM}$ that contained introjected regulation. Normally, a PEB is an extra-role behaviour that employees performing PEBs do not obtain many rewards (Chou, 2014). Therefore, introjected regulation (e.g. I feel guilty without engaging in environmental behaviour at work) may have a deep influence on the study's results that presented the positive relationship between CM and employees' PEBs.

The study confirmed $\mathrm{H} 3$ that AM was positively related to ECs. Because ECs were considered as attitudes with regarding to environment (Luo \& Deng, 2008), the finding was explained by the fact that motivation contributed to employee positive attitude at work (Arnold et al., 2016). Moreover, the relationship between AM and ECs was the strongest among all variables' relationships in the study (shown on Table 4). However, a positive relationship between CM and ECs (H4) was rejected, which seemed to disagree with the previous study by Kim et al. (2016). It strengthened that employees' autonomy deeply reflected their attitudes (Gagné \& Deci, 2005).

H5 about the relationship between ECs and PEBs was supported. This finding's result seemed to contradict the study by Gamba \& Oskamp (1994), but it resonated with the research of Chan et al. (2014) that verified the positive relationship between ECs and ecological behaviours in the hotel industry. This finding can be explained by the theory of planned behaviour which illustrates that behaviours are influenced by attitudes (Ajzen and Madden, 1986).

Furthermore, the study also emphasised the mediating effect between AM and PEBs. The results indicated that AM was not only directly related to PEBs, but also had an indirect relationship with PEBs, mediated by ECs. Even though the previous studies by Graves et al. (2013) and Kim et al. (2016) verified the positive relationship between employee motivation and PEBs, mediating effects between the two variables were not shown. Therefore, the study 
filled this research gap. The finding demonstrating the interaction among AM, ECs and PEBs was consistent with the research of Ambrose and Kulik (1999) which held a viewpoint that motivation was a predictor of both attitudes and behaviours. As noted above, the finding demonstrated that AM was more desirable to enhance ECs than PEBs, so the mediating effect provided a validly indirect way in facilitating PEBs.

\section{Conclusion and implications}

This study focused on IHCs in China and undertook quantitative research to investigate and assess determinants of PEBs at IHCs from employees' perspectives. According to assessment of the structural model, the results verified that both AM and CM had a direct and positive relationship with employees' PEBs. Besides, ECs, acting as a mediator of relationship between AM and employees' PEBs, directly contributed to employees' PEBs improvement. The key implications were listed as follows:

\subsection{Theoretical implications}

Firstly, there is little research on employees' PEBs of IHCs in China (Graves et al., 2013), so the primary contribution with this study is to fill this research gap through testing and assessing the relationship between employee motivation and PEBs. Graves et al. (2013) and Kim et al. (2016) tested the relationship between employee motivation and PEBs based on selfdetermination theory. Both of their studies used two motivation variables (autonomous and external motivation). This study moves a step forward to investigate and assess impacts of AM and CM (external motivation/regulation is a part of CM) on employees' PEBs. It is indicated that not only external regulation (e.g. rewarding) but also introjected regulation (e.g. green social and family situations push employees to perform green activities for shame avoidance) impact on employees' PEBs at IHCs in China. However, the study did not support the relationship between $\mathrm{CM}$ and ECs. It is suggested that $\mathrm{CM}$ is converted to AM for positive attitude developing, which is consistent with self-determination theory (Gagné \& Deci, 2005; Ryan \& Deci, 2000).

Secondly, the study presents an update about the interaction among employee motivation, attitudes and behaviours. AM is directly related to ECs and PEBs (Chan et al., 2014; Kim et al., 2016), but the study confirms the strongest relationship between AM and ECs among all variables' relationships and the ECs' mediating role of the relationship between AM and employees' PEBs. Therefore, the study makes the mediating role of ECs valid and useful for promoting employees' PEBs at IHCs in China. Demonstrating the mediating role of ECs also contribution to the extension of how and why employee motivation impacts on PEBs in the hotel industry. Furthermore, because IHCs are embedded into service-oriented industry, employees' attitudes and behaviours are critical for IHCs' development in the hotel market (Amissah et al., 2016). The study's assessment about the interaction among employee motivation, ECs and PEBs may be helpful for further research with regard to how employee motivation promotes positive attitudes and behaviours at IHCs.

\subsection{Practical implications}

Firstly, each IHC is recommended to coach and mentor employees, which concentrates on developing employees internal value linked with the environment and promoting their competence and determination of dealing with environmental challenges (Kim et al., 2016). However, it is a complicated and long-term job (Arnold et al., 2016). In this way, environmental 
leadership at IHCs plays a principal role in the process of AM (Graves et al., 2013). For example, leaders at IHCs are required to create and strengthen a green organisational climate, such as promoting environmental training and publicising environmental policies (Chou, 2014). When employees feel competent and meaningful to environmental activities, they will be autonomous to persist in PEBs, which is the assumption of self-determination theory to AM (Gagné \& Deci, 2005).

Secondly, as indicated above, the study's results demonstrate that the effect of CM on PEBs cannot be ignored at IHCs. Even though a PEB is an extra role in the workplace (Chou, 2014), IHCs are still required to pay much attention to external rewards in facilitating employees' PEBs (Kim et al., 2016). Furthermore, leaders who establish a green example for all employees at IHCs will be desirable to make employees guilty without green behaviour. It is consistent with the assumption of introjected regulation in self-determination theory (Gagné \& Deci, 2005; Ryan \& Deci, 2000).

Thirdly, the study has verified that the interaction between AM and ECs has the stronger relationship than any other one. Therefore, IHCs cannot merely concentrate on how employees perform their PEBs through motivation. Instead, enhancing employees' environmental attitudes (e.g. environmental concerns) should also be a focus (Chan et al., 2014). Specifically, IHCs are required to assess whether employees' ECs are improved through AM. As ECs are enhanced, it will contribute to employees actively engaging in PEBs. It is consistent with the research by Ajzen \& Madden (1986). According to Chane et al. (2014), Kim et al. (2016) and Miao \& Wei (2013), ECs have been presented to link with PEBs of consumers, but to scarcely relate with PEBs of employees.

\subsection{Limitations and future research}

Despite the research contributions, this study has several limitations which should be considered as direction for future research. Firstly, this research was conducted in only one of Chinese western cities. To fully understand the situation of the Chinese western region, more cities need to be considered as research location. Secondly, the study did not distinguish employees from different position levels. Effects of AM and CM to employees from different position levels may be different, so it is worthwhile to compare impacts of employee motivation on PEBs in different position levels. Thirdly, green organisational climates, which include the companies' environmental policies may positively influence on employees' attitudes and behaviours. In this way, considering green organisational climates as a variable in the theoretical model could verify this.

\section{References}

Ambrose, M.L. \& Kulik, C.T. (1999). Old friends, new faces: motivation research in the 1990s. Journal of Management, 25(3), 231-292.

Amissah, E. F., Gamor, E., Deri, M. N. \& Amissah, A. (2016). Factors influencing employee job satisfaction in Ghana's hotel industry. Journal of Human Resources in Hospitality \& Tourism, 15(2), 166-183.

Arnold, J., Randall, R., Patterson, F., Silvester, J., Robertson, I., Cooper, C., Burnes, B., Swailes, S., Harris, D., Axtell, C. \& Hartog, D. D. (2016). Work psychology : understanding human behaviour in the workplace (6th ed.). Harlow: Pearson Education Limited. 
Al Sabi, S., Masadeh, M., Maaiah, B. \& Al Ababneh, M. (2017). Foreign training in Jordan's international hotel chains: A quantitative investigation. Tourism \& Management Studies, 13(2), 41-51.

Ajzen, I. \& Madden, T.J. (1986). Prediction of goal-directed behavior: Attitudes, intentions, and perceived behavioral control. Journal of Experimental Social Psychology, 22, 453-474.

Banyan Tree. (2018). Banyan Tree Chongqing Beibei. Retrieved March 18, 2018 from http://www.chongqing-byhotel.com

Baron, R. M. \& D. A. Kenny. (1986). The moderator-mediator variable distinction in social psychological research: Conceptual, strategic, and statistical considerations. Journal of Personality and Social Psychology, 51(6), 1173-1182.

Chan, E. S. W., Hon, A. H. Y., Chan, W. \& Okumus, F. (2014). What drives employees' intentions to implement green practices in hotels? The role of knowledge, awareness, concern and ecological behaviour. International Journal of Hospitality Management, 40, 20-28.

Chen, Q. \& Huang, R. (2018). Local food in China: A viable destination attraction. British Food Journal, 120(1), 146-157.

Chen, X., Peterson, M. N., Hull, V., Lu, C., Lee, G. D., Hong, D. \& Liu, J. (2011). Effects of attitudinal and sociodemographic factors on pro-environmental behaviour in urban China. Environmental Conservation, 38(1), 45-52.

Chiang, C.-F. \& Jang, S. (2008). An expectancy theory model for hotel employee motivation. International Journal of Hospitality Management, 27(2), 313-322.

China. (2017). GDP growth rate competition in 31 provinces: Chongqing ranked top one, and only Liaoning was negative growth. Retrieved December 26, 2017 from http://guoqing.china.com.cn/2017-03/14/content_40453325.htm

Chin, W.W. (1998). The partial least squares approach for structural equation modelling. In G.A. Marcoulides (Ed.), Modern methods for business research (pp. 295-336). Mahwah: Lawrence Erlbaum Association.

Chinese National Tourism Administration. (2002). The Yearbook of China Tourism Statistics. Beijing: China Tourism.

Chongqing Municipal People's Government. (2017). Overview of Chongqing. Retrieved December 18, 2017 from http://www.cq.gov.cn/cqgk/82833.shtml

Chou, C.-J. (2014). Hotels' environmental policies and employee personal environmental beliefs: Interactions and outcomes. Tourism Management, 40, 436-446.

Chun-Fang, C., SooCheong, J., Canter, D. \& Prince, B. (2008). An Expectancy Theory Model for Hotel Employee Motivation: Examining the Moderating Role of Communication Satisfaction. International Journal of Hospitality \& Tourism Administration, 9(4), 327-351. 
Clark, C. F., Kotchen, M. J. \& Moore, M. R. (2003). Internal and external influences on proenvironmental behavior: Participation in a green electricity program. Journal of Environmental Psychology, 23(3), 237-246.

Daily, B.F., Bishop, J.W. \& Govindarajulu, N. (2009). A conceptual model for organizational citizenship behaviour directed toward the environment. Business \& Society, 48, 243-256.

Darner, R. (2009), "Self-Determination Theory as a Guide to Fostering Environmental Motivation”, Journal of Environmental Education, 40(2), 39-49.

Deci, E. L. \& Ryan, R. M. (2000). The "what" and "why" of goal pursuits: Human needs and the self-determination of behavior. Psychological Inquiry, 11(4), 227-268.

Fink, A. (2013). How to conduct survey: A step-by-step guide (5th ed.). California: Sage Publications,

Fornell, C. \& Larcker, D.F. (1981). Evaluating structural equation models with unobservable variables and measurement error. Journal of Marketing Research, 18(2), 161-188.

Gagné, M. \& Deci, E. L. (2005). Self- determination theory and work motivation. Journal of Organizational Behavior, 26(4), 331-362.

Gagné, M., Forest, J., Vansteenkiste, M., Crevier-Braud, L., van Den Broeck, A., Aspeli, A. K., Bellerose, J., Benabou, C., Chemolli, E., Güntert, S. T., Halvari, H., Indiyastuti, D. L., Johnson, P. A., Molstad, M. H., Naudin, M., Ndao, A., Olafsen, A. H., Roussel, P., Wang, Z. $\&$ Westbye, C. (2015). The Multidimensional work motivation scale: Validation evidence in seven languages and nine countries. European Journal of Work and Organizational Psychology, 24(2), 178-196.

Gamba, R.J. \& Oskamp, S. (1994). Factors influencing community residents' participation in commingled curbside recycling programs. Environmental Behaviour, 26(5), 587-612.

Gatling, A., Kim, J. \& Milliman, J. (2016). The relationship between workplace spirituality and hospitality supervisors' work attitudes: A self-determination theory perspective.

International Journal of Contemporary Hospitality Management, 28(3), 471-489.

Graves, L. M., Sarkis, J. \& Zhu, Q. (2013). How transformational leadership and employee motivation combine to predict employee proenvironmental behaviors in China. Journal of Environmental Psychology, 35, 81-91.

Hair, J.F., Hult, G.T.M., Ringle, C.M. \& Sarstedt, M. (2017). A primer on partial least squares structural equation modeling (PLS-SEM) (2nd ed.). London: SAGE Publications.

Hair, J.F., Ringle, C.M. \& Sarstedt, M. (2011). PLS-SEM: Indeed a silver bullet. Jounral of Marketing Theory and Practice, 19(2), 139-151.

Henseler, J., Ringle, C. M. \& Sinkovics, R. R. (2009). The use of partial least squares path modelling in international marketing. Advances in International Marketing, 20(1), 277-320. 
Hilton. (2018). Chongqing. Retrieved March 18, 2018 from http://www.hilton.com.cn/zh-CN/city/Chongqing-hotels.html

Hofmann, D. A., Morgeson, F. P. \& Gerras, S. J. (2003). Climate as a Moderator of the Relationship Between Leader-Member Exchange and Content Specific Citizenship: Safety Climate as an Exemplar. Journal of Applied Psychology, 88(1), 170-178.

Hung, K. \& Law, R. (2011). An overview of Internet- based surveys in hospitality and tourism journals. Tourism Management, 32(4), 717-724.

Kim, S.-H., Kim, M., Han, H.-S. \& Holland, S. (2016). The determinants of hospitality employees' pro-environmental behaviors: The moderating role of generational differences. International Journal of Hospitality Management, 52, 56-67.

Kim, C. S., Bai, B. H., Kim, P. B. \& Chon, K. (2018). Review of reviews: A systematic analysis of review papers in the hospitality and tourism literature. International Journal of Hospitality Management, 70, 49-58.

Kock, N. \& Hadaya, P. (2018). Minimum sample size estimation in PLS-SEM: The inverse square root and gamma-exponential methods. Information Systems Journal, 28, 227-261.

Law, R., Wu, J. \& Liu, J. (2014). Progress in Chinese hotel research: A review of SSCI-listed journals. International Journal of Hospitality Management, 42, 144-154.

Lee, Y.K., Kim, S. and Choi, J.G. (2014). Antecedents and interrelationships of three types of pro-environmental behavior. Journal of Business Research, 67, 2097-2105.

Luo, Y. \& Deng, J. (2008). The new enviornemntal paradigm and nature-based tourism motivation. Jounral of Travel Research, 46(4), 392-402.

Miao, L. \& Wei, W. (2013). Consumers' pro-environmental behaviour and the underlying motivations: A comparison between household and hotel settings. International Journal of Hospitality Management, 32, 102-112.

Nitzl, C., Roldan, J.L. \& Cepeda, G. (2016). Mediation analysis in partial least squares path modeling: Helping researchers discuss more sophisticated models. Industrial Management \& Data Analysis, 116(9), 1849-1864.

Peng, D.X. \& Lai, F. (2012). Using partial least squares in operations management research: A practical guideline and summary of past research. Journal of Operations Management, 30, 467480 .

Rahman, I., Reynolds, D. \& Svaren, S. (2012). How "green" are North American hotels? An exploration of low-cost adoption practices. International Journal of Hospitality Management, 31(3), 720-727.

Robertson, J. L. \& Barling, J. (2013). Greening organizations through leaders' influence on employees' pro-environmental behaviors. Journal of Organizational Behavior, 34(2), 176-194. 
Ryan, R. M. \& Deci, E. L. (2000). Intrinsic and extrinsic motivations: Classic definitions and new directions. Contemporary Educational Psychology, 25(1), 54-67.

Sarstedt, M., Wilczynski, P. and Melewar, T.C. (2013). Measuring reputation in global markets: A comparison of reputation measures' convergent and criterion validities. Journal of World Business, 48(3), 329-339.

Schultz, P. W., Shriver, C., Tabanico, J. J. \& Khazian, A. M. (2004). Implicit connections with nature. Journal of Environmental Psychology, 24(1), 31-42.

Tsang, N. \& Hsu, C. (2011). Thirty years of research on tourism and hospitality management in China: A review and analysis of journal publications. International Journal of Hospitality Management, 30(4), 886-896.

Tsang, N., Lee, L. \& Qu, H. (2015). Service quality research on China's hospitality and tourism industry. International Journal of Contemporary Hospitality Management, 27(3), 473-497.

Welters, R., Mitchell, W. \& Muysken, J. (2014). Self determination theory and employed job search. Journal of Economic Psychology, 44, 34-44.

Zhang, Q.H., Guillet, B.D. \& Gao, W. (2012). What determines multinational hotel groups' locational investment choice in China? International Journal of Hospitality Management, 31(2), 350-359. 
Table 1

Profile of respondents (responses: 181)

\begin{tabular}{llll}
\hline Variables & & Frequency & Percent \\
\hline Gender & Male & 56 & 30.9 \\
Education & Female & 125 & 69.1 \\
& Diploma or below & 72 & 39.8 \\
Position classification & Bachelor degree & 97 & 53.6 \\
& Master degree or above & 12 & 6.6 \\
& Employee & 30 & 16.6 \\
& Supervisor & 11 & 6.1 \\
Years of work experience & Department manager & 15 & 8.3 \\
& Director & 4 & 2.2 \\
International hotel groups & Not indicated & 121 & 66.9 \\
& 3 years or less & 66 & 36.5 \\
& 4-10 years & 74 & 40.9 \\
& More than 10 years & 41 & 22.7 \\
& Banyan Tree Holdings & 2 & 1.1 \\
& Hilton Hotels \& Resorts & 40 & 22.1 \\
& Hyatt Hotels Corporation & 9 & 5.0 \\
& InterContinental Hotels Group & 18 & 10.0 \\
& Kempinski Hotels & 6 & 3.3 \\
& Marriott International & 65 & 35.9 \\
& Radisson Hotel Group & 4 & 2.2 \\
& Regent Hotels \& Resorts & 21 & 11.6 \\
& Wyndham Hotels \& Resorts & 16 & 8.9 \\
\hline
\end{tabular}

Table 2

Assessment of reflective measurement model

\begin{tabular}{|c|c|c|c|c|}
\hline Constructs and items & Loading & Cranach's Alpha & Composite reliability & AVE \\
\hline $\begin{array}{l}\text { Pro-environmental behaviours } \\
\end{array}$ & & 0.912 & 0.926 & 0.586 \\
\hline $\begin{array}{l}\text { 1: At work, I try to learn more about the } \\
\text { environment. }\end{array}$ & 0.825 & & & \\
\hline $\begin{array}{l}\text { 2: At work, I find the ways of working that are } \\
\text { better for the environment. }\end{array}$ & 0.794 & & & \\
\hline 3: At work, I try not to waste water. & 0.829 & & & \\
\hline $\begin{array}{l}\text { 4: At work, I perform environmental tasks that are } \\
\text { not required by the hotel. }\end{array}$ & 0.638 & & & \\
\hline $\begin{array}{l}\text { 5: At work, I join in environmental activities that } \\
\text { are not required by my job. }\end{array}$ & 0.691 & & & \\
\hline $\begin{array}{l}\text { 6: At work, I encourage others to think about the } \\
\text { environment. }\end{array}$ & 0.852 & & & \\
\hline $\begin{array}{l}\text { 7: At work, when the environmentally unfriendly } \\
\text { behaviour happens, I will prevent timely. } \\
\text { 8: At work, I question practices that are likely to }\end{array}$ & 0.838 & & & \\
\hline $\begin{array}{l}\text { hurt the environment. } \\
\text { hentas }\end{array}$ & 0.661 & & & \\
\hline $\begin{array}{l}\text { 9: At work, I try to save resources possessed by the } \\
\text { hotel. }\end{array}$ & 0.723 & & & \\
\hline $\begin{array}{l}\text { Environmental concerns } \\
\text { 1: We are approaching the limit of number of } \\
\text { people the earth can support. }\end{array}$ & 0.7 & 0.853 & 0.891 & 0.579 \\
\hline $\begin{array}{l}\text { 2: The balance of nature is very delicate and easily } \\
\text { gets upset. } \\
\text { 3: Plants and animals have as much right as humans }\end{array}$ & 0.785 & & & \\
\hline $\begin{array}{l}\text { to exist. } \\
\text { 4: If things continue on their present course, we will }\end{array}$ & 0.837 & & & \\
\hline
\end{tabular}


5: Global warming threats the existence of human beings.

6: Air quality is gradually worse.

0.672

Table 3

Assessment of the formative measurement model

\begin{tabular}{|c|c|c|c|}
\hline Constructs and items & VIF & Outer weights & Outer loadings \\
\hline \multicolumn{4}{|l|}{ Autonomous motivation } \\
\hline $\begin{array}{l}\text { 1: I will engage in green behaviour at work because I am interested } \\
\text { in it. }\end{array}$ & 3.218 & $0.502 * *$ & $0.843 * *$ \\
\hline $\begin{array}{l}\text { 2: I will engage in green behaviour at work because } 1 \text { think } \\
\text { everyone takes a responsibility to do it. }\end{array}$ & 2.848 & 0.184 & $0.856 * *$ \\
\hline $\begin{array}{l}\text { 3: I will engage in green behaviour at work because I get pleasure } \\
\text { by doing it. }\end{array}$ & 3.711 & -0.149 & $0.759 * *$ \\
\hline $\begin{array}{l}\text { 4: I will engage in green behaviour at work because I think it is } \\
\text { important. }\end{array}$ & 3.457 & $0.581 * *$ & $0.916 * *$ \\
\hline $\begin{array}{l}\text { Global: I will engage in green behaviour at work because it fits my } \\
\text { personal values. }\end{array}$ & 1 & & \\
\hline \multicolumn{4}{|l|}{ Controlled motivation } \\
\hline $\begin{array}{l}\text { 1: I will engage in green behaviour at work because the hotel asks } \\
\text { me to do it. }\end{array}$ & 1.338 & $0.743 * *$ & $0.939 * *$ \\
\hline $\begin{array}{l}\text { 2: I will engage in green behaviour at work because the hotel will } \\
\text { reward me by doing it. }\end{array}$ & 2.524 & 0.214 & $0.74 * *$ \\
\hline $\begin{array}{l}\text { 3: I will engage in green behaviour at work because I am driven } \\
\text { by social environment, or I will feel guilty. }\end{array}$ & 2.331 & $0.209 *$ & $0.688 * *$ \\
\hline $\begin{array}{l}\text { 4: I will engage in green behaviour at work, because I am driven } \\
\text { by family members who enjoy green behaviour, or I will feel } \\
\text { guilty. }\end{array}$ & 1.258 & & \\
\hline $\begin{array}{l}\text { 5: I will engage in green behaviour at work because I am driven } \\
\text { by my friends who enjoy green behaviour, or I will feel guilty. }\end{array}$ & 1.258 & & \\
\hline
\end{tabular}
$* p<0.05$

$* * p<0.01$

Table 4

Significance and relevance of the path coefficients

\begin{tabular}{llll}
\hline Hypotheses & Path coefficient & $t$-values & Results \\
\hline H1: AM -> PEBs & $0.329^{* *}$ & 4.175 & Supported \\
H2: CM -> PEBs & $0.337^{* *}$ & 4.289 & Supported \\
H3: AM -> environmental concerns & $0.545^{* *}$ & 6.045 & Supported \\
H4: CM -> environmental concerns & 0.076 & 1.016 & Rejected \\
H5: ECs $>$ PEBs & $0.267^{* *}$ & 3.548 & Supported \\
\hline
\end{tabular}

$* p<0.05$

$* * p<0.01$

Table 5

Mediating effects

\begin{tabular}{ll}
\hline Type of mediation & Explanation \\
\hline No mediation & Both direct effect and indirect effect are not significant. Theoretical model is invalid. \\
& Or direct effect is significant, but indirect effect is not. \\
Partial mediation & Both direct effect and indirect effect are significant. \\
Full mediation & Indirect effect is significant, but direct effect is not. \\
\hline
\end{tabular}

Source: adapted from Nitzl et al. (2016) 
Table 6

Mediation test by Bootstrapping

\begin{tabular}{|c|c|c|c|c|c|c|}
\hline & \multirow{2}{*}{$\begin{array}{l}\text { Mediator } \\
\text { variable }\end{array}$} & \multicolumn{2}{|c|}{ Direct effect } & \multicolumn{2}{|c|}{ Indirect effect } & \multirow[t]{2}{*}{ Mediation } \\
\hline & & $t$-values & Sig. ( $p$ values $)$ & $t$-values & Sig. ( $p$ values $)$ & \\
\hline $\mathrm{CM}$-> PEBs & $\mathrm{EC}$ & 4.364 & $* * 0.000$ & 0.951 & 0.342 & No mediation \\
\hline $\mathrm{AM}->$ PEBs & $\mathrm{EC}$ & 4.248 & $* * 0.000$ & 3.462 & $* * 0.001$ & $\begin{array}{l}\text { Partial } \\
\text { mediation }\end{array}$ \\
\hline
\end{tabular}


Fig. 1. The theoretical model.

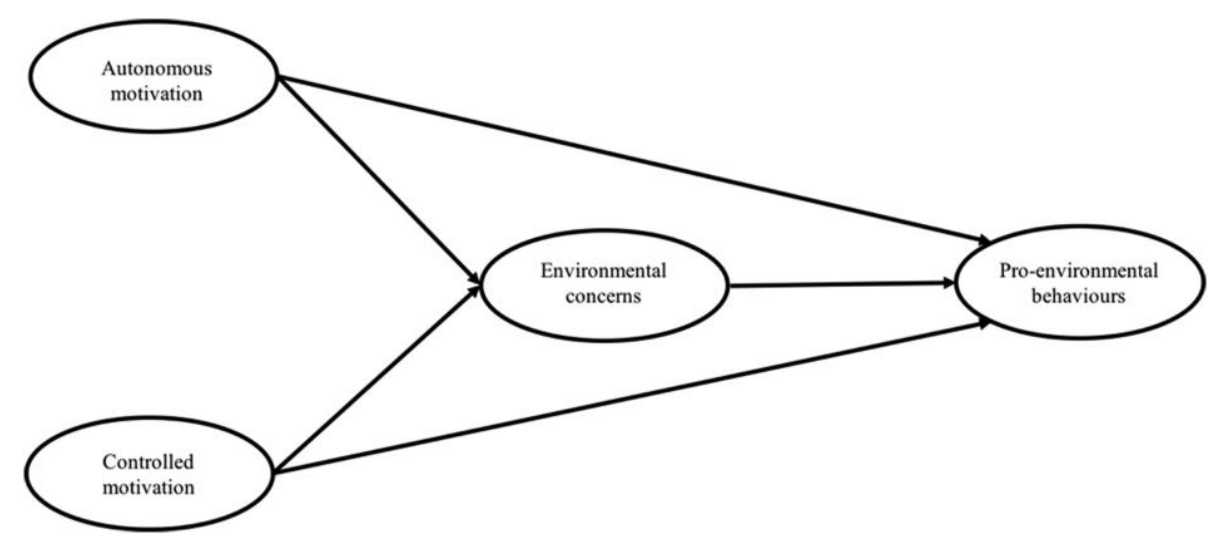

Fig. 2. Formative measurement model: Redundancy analysis.
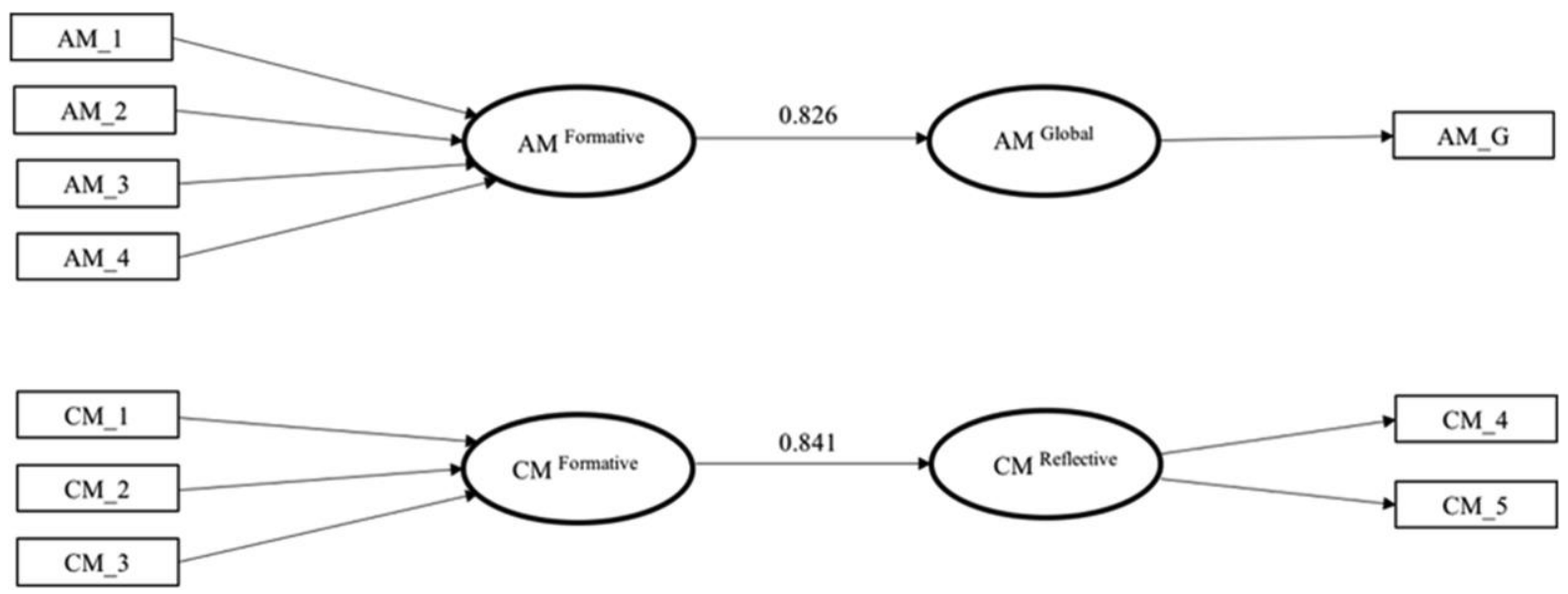